\title{
Grandparents battle to be key stakeholders in protecting grandchildren
}

Susan Gair ${ }^{1}$, Ines Zuchowski ${ }^{1}$, Debbie Henderson ${ }^{2}$, Ros Thorpe ${ }^{3}$ and Lyn Munns ${ }^{1}$

\begin{abstract}
INTRODUCTION: Grandparents are increasingly involved in the care of grandchildren, including after child protection intervention.

METHOD: A recent Australian qualitative research partnership explored how relationships between grandparents and their grandchildren could be optimised after child safety concerns. Interviews and focus groups were undertaken with 77 participants, including 51 grandparents, 12 parents, six foster carers and eight child and family workers. Emerging themes reported here focus on the role of grandparents and their perceptions of, and interactions with, the child protection system.
\end{abstract}

FINDINGS: Overall, findings identify that grandparents wanted to help safeguard their grandchildren but many encountered an adversarial child protection system that left them feeling powerless, fearful and unimportant. Aboriginal participants reiterated that child protection workers needed to better understand how maintaining kinship networks provided a protective factor for Aboriginal children, and that grandparents were key stakeholders in their grandchildren's lives.

IMPLICATIONS: The findings from this study affirm the value and role of grandparents and highlight the need for implemented family-inclusive child protection practice within and beyond the Australian context.

KEYWORDS: Grandparents, grandchildren; family-inclusive child protection practice
1 James Cook University, Townsville, Queensland

${ }^{2}$ Family Inclusion Network, Western Australia

${ }^{3}$ Family Inclusion Network, Townsville, Queensland
The number of Australian children receiving formal child protection services continues to trend upwards although some variation exists across Australian states and territories. According to the Australian Institute of Health and Welfare (AIHW), during 2016-2017, 168,352 children had an investigation, care and protection order and/or were placed in out-ofhome care, including kinship care, an increase on previous years (AIHW, 2017, 2018). AIHW (2018, p. 46) reported that, for jurisdictions with available data in 2016-2017, 52\% of kinship carers were grandparents, while $20 \%$ were aunts/uncles. Similarly, growing numbers of grandparents internationally undertake the carer role for grandchildren (Hunt, 2018; Thomson, Cameron, \& Fuller-Thomson, 2013). Elsewhere in the literature, grandparents have reported disrupted and denied contact with grandchildren including after child protection intervention (Cox, 2014; Drew \& Silverstein, 2007; Gair, 2017).

For Australian Aboriginal and Torres Strait Islander peoples, the grandparent carer role is core to their cultural responsibilities,
AOTEAROA

NEW ZEALAND SOCIAL WORK 31(1), 101-113.

CORRESPONDENCE TO: Susan Gair susan.gair@jcu.edu.au 
providing children with strong crossgenerational relationships (Secretariat of National Aboriginal and Islander Child Care (SNAICC), 2010). The forced removal of Aboriginal children in the past is said to have severely damaged family networks and culturally, psychologically and geographically distanced grandparents from their caring responsibilities and their grandchildren (Thomson et al., 2013). Grandparent carers often step in when there are family breakdowns or when children are deemed to be at risk of harm, and kinship placements can help maintain children's wellbeing and family connections. However, the true extent of informal grandparent care may be extremely difficult to ascertain, particularly for Aboriginal and Torres Strait Islander families (SNAICC, 2010).

It has been reported that child protection systems in Australia are in crisis, with increased numbers of children in care resulting in unsustainable caseloads for workers. Further, it has been suggested that a risk-averse organisational culture, and non-Indigenous child protection workers' lack of understanding of cultural values underpinning Aboriginal child rearing, are contributing to increased numbers of children coming into state care (Carmody, 2013; Child Protection Peak, 2017; Child Protection Systems Royal Commission, 2016; Lonne, Harries, Featherstone, \& Gray, 2016).

A recent Australian qualitative study explored how grandparent-grandchild relationships could be optimised after child safety concerns. The research was informed by findings from an earlier, small study suggesting grandparents struggled to be heard in relation to their grandchildren's care and risk of harm (Rigby, Gair, \& Thorpe, 2016). Only limited Australian research on this topic was identified. Some findings have been published elsewhere (Gair, Zuchowski, Munns, Thorpe, \& Henderson, 2018; Zuchowski, Gair, Henderson, \& Thorpe, 2018). This article specifically focuses on participants' perceptions and interactions with child protection workers and systems.

\section{Background}

\section{Grandparent carers}

International and national literature identifies the growing role of grandparents as full-time carers for their grandchildren, often due to family breakdown, substance abuse by adult children, family violence, poor parental mental health, poverty, housing instability, an absent or incarcerated parent, and where parents are unable to care for children (Backhouse \& Graham, 2012; Irizarry, Miller, \& Bowden, 2016). It has been reported that kinship placements can provide greater placement stability than foster care and give greater child wellbeing, although not all researchers agree (Farmer, 2009; Hunt, 2018; Winokur, Holtan, \& Batchelder, 2014). Hunt (2018) reported that often grandparent carers are grandmothers caring alone. While growing kinship care literature in the Australian context is evident, the importance of the grandparent role when children are removed into State care, and grandparents' inclusion in decision-making about their grandchildren's care appears less evident.

In Aboriginal and Torres Strait Islander cultures, extended families play a critical role in the protection and rearing of children, and grandparents, aunties and uncles all have parenting responsibilities (AIHW, 2018; Ivec, Braithwaite, \& Harris, 2012; SNAICC, 2010). Some researchers have reported that, while non-Indigenous grandparent carers may see the full-time carer role as culturally nonnormative and an unexpected challenge in later life, many Aboriginal kinship carers see the role as a familiar, cultural obligation that also can break the cycle of inter-generational child protection intervention (Hunt, 2018; Milosevic, Thorpe, \& Miles, 2009).

Much of the Australian literature on grandparent carers identifies that they often do not receive the professional support or resources necessary to meet their own and their grandchildren's needs, particularly for children with complex trauma. Grandparent 
kinship carers reportedly are less likely than foster carers to be offered respite care, training and adequate allowances; they often are less well-off and older than non-relative foster carers; and some kinship carers experience limited follow-up from workers (Farmer, 2009; Irizarry et al., 2016; Qu, Lahausse, \& Carson, 2018).

\section{Child protection and intervention}

Child protection practice in the best interests of children. In Australia, individual State and Territory governments are responsible for the statutory protection of vulnerable children. A strong underpinning discourse at the heart of child protection legislation across Australia and internationally is said to be decision-making in the best interests of children, as aligned with the International Convention on the Rights of the Child (Lonne et al., 2016). Yet consensus on what constitutes these best interests, particularly in decision-making for children's long-term best interests is less evident (Keddell, 2017, p. 324; Ramsden, 2013). Long and Sephton (2011, p. 97) argued that the distinct "best interests of Aboriginal children" were misunderstood in service provision.

It is recognised that child protection work involves workers making stressful and difficult decisions in highly complex contexts (Lonne et al., 2016; Morris \& Burford, 2017). Correspondingly, the profound impacts on families of such decisions have been documented over time including their feelings of anger, grief, powerlessness, fear, and shame (Ainsworth \& Berger, 2014; Dumbrill, 2010; Lonne et al., 2016; Thoburn, Lewis, \& Shemmings, 1995). Buckley (2017) described how families can become stigmatised and vulnerable in investigation cycles and impoverished circumstances. Increasingly, poverty is recognised as a factor in child mistreatment both nationally and internationally, while improved income is a protective factor (Raissian \& Bullinger, 2017). Backhouse and Graham (2012, p. 313) revealed that there also is a stigma for grandparents caring for their grandchildren after child protection concerns, and that grandparents often feel they are viewed as "somehow responsible for what's gone wrong" in the family.

In both Australian and international contexts, it has been argued that heavy caseloads, limited time to build relationships with families, narrow risk assessment tools and insufficient worker skills are hindering child protection work in partnership with families (Alfandari, 2017; Morris, White, Doherty, \& Warwick, 2017). Further impediments include media reporting of known child deaths, the individualism engendered by neoliberalism, and a prevailing, risk-averse, "paternalistic organisational culture" (Alfandari, 2017, p 1061; Buckley, 2017; Beddoe \& Cree, 2017, Morris \& Burford, 2017; Parton, 2017). While parental 'readiness to change' is an identified reunification factor, Humphreys, Thiara, and Skamballis, (2011, p. 166) argued that organisational 'readiness to change' is required to facilitate a cultural shift in practice after new policy directives. Similarly, Smith et al. (2017) noted the difficulties of effecting change in frontline child protection services.

\section{Aboriginal and Torres Strait Islander children and families}

The Bringing Them Home Report (Human Rights and Equal Opportunity Commission (HREOC), 1997) highlighted the traumatic legacies of past removals of Aboriginal children, known as the Stolen Generation. However, since that time the rate of child removals has been unprecedented (Funston, Herring \& Aboriginal Communities Matter Advisory Group (ACMAG), 2016). In 20162017, Aboriginal and Torres Strait Islander children were up to 10 times more likely than non-Indigenous children to be involved with child protection services (AIHW, 2018; SNAICC, 2017). In reviewing child protection services in Queensland, a state where there are high numbers of Aboriginal and Torres Strait Islanders families, The Carmody Report (Carmody, 2013) 
highlighted the inadequate application of the Aboriginal and Torres Strait Islander Child Placement Principle (the Child Placement Principle), implemented specifically to prioritise placements of children within family, culture and community. This report also recommended improvements to the recruitment and retention of kinship carers. Yet, in 2016-2017, only 68\% of Aboriginal and Torres Strait Islander children in care reportedly were placed in accordance with the Child Placement Principle (AIHW, 2018, p. 48). Equally, SNAICC (2018, p. 5) argued that children are not being placed in "genuine kinship placements", kinship is being defined "far too broadly", and that community members with "knowledge and authority to determine the most appropriate placements" are not being consulted. That report has called for new national standards, strategies and targets to arrest the alarming future projections of Indigenous children under statutory care.

Further, Herring, Spangaro, Lauwa, and McNamara (2013) highlighted the lack of accounting for systemic issues creating discrepancies between Aboriginal and non-Aboriginal Australians' life trajectories such as poverty and the ongoing racism experienced by Aboriginal people. Elsewhere, drug and alcohol misuse and family violence have been identified as factors in the over-representation of Aboriginal and Torres Strait Islander children in child protection services (AIHW, 2017; HREOC, 1997; Ivec et al., 2012). Yet Kickett-Tucker and Hansen (2017) stated that, while legacies of trauma lingered because of past child removals, many Aboriginal people are intimately connected to culture and family networks. More specifically, Lohoar, Butera, and Kennedy (2014, p. 2) argued that culture was a strong "protective force", helping children build confidence through freedom to explore under the watchful eye of family and community, and that "overexaggerating safety risks can reduce children's resilience" and place children "at risk in the long-term" (p. 11).
"Closing the Gap" strategies that target poverty, early childhood health and education, rebuilding family connections, addressing racism, and reducing the gap in education and employment outcomes are considered pivotal in reducing Aboriginal and Torres Strait Islander children's vulnerability to involvement in child protection processes (Department of Prime Minister and Cabinet, 2017). The three-year action plan (2015-2018) of the National Framework for Protecting Australian Children 2009-2020 promised improved outcomes for children (Council of Australian Governments (COAG), 2014). However, the rate of Indigenous children receiving child protection services has continued to rise (SNAICC, 2017), in turn perpetuating trauma for vulnerable families, and expanding the workload of overstretched child protection services. While many grandparent carers seek to play an increased role in protecting grandchildren, literature supporting and upholding their valuable role and inclusion in decision-making about their grandchildren's care appears less evident.

\section{Methodology}

The research question posed in the qualitative study reported here was: What are the ways that grandparent-grandchild connections can be optimised in child protection intervention, out of home care and related services? The primary aim was to document the narratives, perceptions and recommendations of participants, and contribute to current knowledge and practice. Semi-structured, open-ended interview questions explored ways to optimise the inclusion of grandparents in child protection/ out of home care/kinship care. The research was approved by a university Human Ethics Committee. Ethical considerations included confidentiality, understanding cultural sensitivities, meaningful engagement with partners, and accountability regarding dissemination of findings to contribute to informed practice. Given the overrepresentation of Aboriginal and Torres Strait Islander families in child protection 
services, the guidance of an Aboriginal Elder was sought across the time of the study, and an Aboriginal researcher joined the research team. The study was funded by a university partnership research grant.

\section{Research partners}

The research was undertaken jointly by university researchers and community organisation partners. The community stakeholders were Family Inclusion Network Queensland (Townsville) (FINTSV), Family Inclusion Network Western Australia (FINWA), organisations that provide support to families with children in care, and Act for Kids, an organisation providing therapy for children at risk. The partners provided guidance and feedback on the aims and research question, and promoted the research within their organisation, networks and client groups. They reviewed and contributed to the data analysis and findings, and were involved in drafting and reviewing manuscripts and blogs for dissemination. While the statutory sector was approached and their participation sought, that partnership did not proceed.

Desired outcomes for the partners were that findings would inform and improve their own practice and child protection practice more broadly, influence child protection policy across Australia, and inform social work education. The ultimate goal for the research partners was for child protection practice to become more receptive to, and inclusive of, families, including grandparents.

\section{Data collection and analysis}

Participants were invited to be involved in this study via flyers distributed through nongovernment agencies, media reporting and use of network sampling (Creswell, 2014). All participants were offered the option of participating in an interview or a focus group. Some focus groups represented a mix of participants, for example, grandparents, parents, and workers. Initially, grandparents were the sole participant group nominated for recruitment. However, one partner organisation identified that, given the exploratory nature of the study, inclusion of child protection workers, foster carers and parents could contribute to increased insight. In total, the sample consisted of 77 participants, including 51 grandparents (45 grandmothers inclusive of aunties (four) in grandmother roles, and six grandfathers), 12 parents (11 mothers, one father), six foster carers (five female, one male) and eight child and family workers (all female). In total, $35 \%$ of the participants in the sample, and $53 \%$ of the grandparent sample identified as Aboriginal or Torres Strait Islander Australians $(n=27)$.

Participants from Queensland, Western Australia, South Australia and Victoria engaged in a total of 28 individual interviews, three couple interviews and seven focus group interviews (43 attendees). Interviews were conducted face to face or over the telephone by three different members of the research collaboration. The focus groups took place face to face and were facilitated predominantly by the same researcher, accompanied by members of a partner organisation. The same interview guide gave direction to both focus groups and interviews. The interviews and focus groups were audio-recorded and transcribed.

In line with an interpretive thematic data analysis process, all transcripts were read multiple times to make initial sense of the qualitative data. As a next step, researchers worked jointly to identify emerging patterns and themes across the focus group and interview data sets, as relevant to the overall research question. After preliminary themes were coded, researchers explored relationships between and across codes (Liamputtong, 2009). At this point the emerging themes were discussed at length and refined with key stakeholder partners. In this article the perspectives and experiences of participants in relation to their interactions with child protection systems, and with child protection workers, are presented. 


\section{Findings}

The five key themes identified below focus on interactions with child protection workers in relation to maintaining connections with grandchildren. These themes are: i) Fears, compliance, powerlessness and resistance; ii) Grandparents excluded in decision making; iii) Workers' power to name the narrative; iv) Fighting the system; and v) New frameworks or "business as usual". In the findings presented later, the voices of grandparents, workers and some parents are included. As recommended by industry partners in this study and, as is evident here, multiple voices helped inform in-depth interpretations of the study findings. Some longer quotes are included to help capture the complex stories being shared.

\section{Fears, compliance, powerlessness and resistance}

Grandparents in this study highly valued their relationships with their grandchildren, and they were conscious of the power of the Department in relation to disrupting these relationships. This point is exemplified in the following comment made in one of the focus groups

[T] he grandparents just want to have some sort of relationship. There's no way they would ever jeopardise that by screwing with their rules. No way! (grandparent, focus group 1)

Similarly, this grandmother had growing fears about disrupted relationships with her grandchildren if they came to the attention of the child protection system, linking these fears to past and present removals of Aboriginal children:

I do fear because of what they do to our Indigenous people within the community ... that's what I fear may happen to myself and to my grandchildren because of ... my son and his partner ... because of where they're at, [and] not having steady jobs .... and the finance[s] and the way they are living at the moment.

(grandmother, interview 30)

Issues of power and powerlessness emerged in comments about the distressing way children were removed, while some resistance also is evident from this participant:

They went to the [other] nan's house and picked up the first lot of kids and they came back .... They got the police involved. I said ... "Look, settle down ... I said to the police, "What happens if they came and took your kids in a bus, what would you do?" And the police said, "If you step forward, we'll arrest you." I said, "You're going to arrest all of us, the whole 50 of us here?" I was really angry." (grandmother, focus group 2)

Other participants highlighted child protection workers' controlling influence over contact visits with their grandchildren, including this grandmother who felt she had no option but to comply:

I had unsupervised visits, and then the next week before I saw my grandchildren they sent out this paper for me to sign it, and if I didn't sign it, that I would not see my grandchildren on that afternoon. And I said no, I'm not going to sign it. And then I thought no, I will sign it, because I have to see my grandchildren .... (grandmother, focus group 1)

Tarrant, Featherstone, O'Dell, and Fraser (2017) argued that workers needed to pay greater attention to grandparents' desire to stay connected to grandchildren, and recognise their fears about losing contact after children when child protection services become involved.

\section{Grandparents excluded in decision making}

Grandparents, parents and workers revealed circumstances where grandparents were excluded from decision-making about the 
placement of a child, even if grandparents ultimately became the kin carer for that grandchild. For instance, this parent expressed confusion that a decision was made about her daughter's placement with the grandmother without consultation with her:

There was this one incident where ... the police removed me to a women's shelter and it took a week and a half for a Child Safety officer to call me back, even though I rang her every day ... and left messages ... I was in a crisis... Mum had put several calls through and got no responses. ... As things progressed it became pretty clear, from stuff that Child Safety said, ... they were going to put [daughter] in my mother's care. And I thought that this was ironic, because they would not talk to her or return her phone calls ... They just did case plans and she wasn't invited ... (parent, interview 12)

Offering a worker's perspective, this participant explained that it is workers who make decisions about placement and arrange contact for children in care, and this could include grandparents, but implied that the workers would use their discretionary power to judge the risks regarding what was in the best interests of children:

... when a child's at home - that's more their parents' responsibility but when a child is in care we will look at family contacts and - as long as it's in the best interests of the child. I mean if the grandparents are nasty towards the child obviously we wouldn't ... (worker, interview 27)

Another worker explained that, while the Child Placement Principle policy was followed, recognition of intergenerational trauma was a reason used to exclude Aboriginal grandparents as carers:

Well the legislation tells us that we need to explore family, um, and already established connections... I think it works especially well when we are looking at Indigenous children, so there is a very clear guided policy around that family need to be explored, and I guess that includes ... well it does include the grandparents as well, but in my experience a lot of the times family and grandparents would be excluded from taking care of children um, because of intergenerational issues, you know, health issues, and often, seeing that intergenerational trauma that's passed on. (worker, interview 17)

Offering a different perspective, this parent was surprised that after specifically naming her extended family members as key supports for her children, that their names were missing from the file as key contacts:

And then when my kids were taken into care, none of my family were contacted. I'm like "well hang on, you've got them down as support". We've only just recently found out that there's stuff missing out of my file, and my family were actually removed from my file, and I had no knowledge of it. (parent, focus group 1)

The findings above support assertions from Morris and Burford (2017, p. 104) that risk aversion in child protection practice has kept families "distanced from decision-making, and often their children".

\section{Workers' power to name the narrative}

While some workers in this study promoted the value of grandparents, many grandparents and parents identified that they were skeptical about trusting department workers to uphold the importance of grandparents in grandchildren's lives. This worker reported actively promoting the value of grandparents to new workers:

I've got ten years' child protection history and I've used grandparents [for] everything... becoming the main provider ... helping them to get custody 
[in] the Children Family Law Court, or ... [when] parents have been incarcerated... anyone that starts at the Department, ... I always go on about it... "keep exploring family"... there is always somebody we can tap into ... and whether that's a grandparent, or an aunty ... it's really important ... so that they know who they are and where they come from... (worker, interview 26)

In contrast, a distrusting stance about departmental workers in relation to grandparents was commonly aired in this study. This included identifying workers' power to name circumstances in a way that misrepresented grandparents and impacted grandparents' contact with grandchildren and their access to support. For example, in a joint interview these grandparents explained how inaccurate information was presented by workers in court documents:

The Department lying in court about apprehending the kids... making up fictitious dates on their court documents and everything like that, and I have actually got the court documents to prove it. (grandparents, interview 19)

This grandparent similarly distrusted the accuracy of information supplied by departmental staff:

The trouble is, you have a care management plan and there is no guarantee that the information that the Department has fed you is accurate. (grandfather, interview 16)

In a different context, while this grandmother wanted formal recognition the grandchildren were living permanently with her and her husband, to enable increased support, Departmental workers named the arrangement as a verbal agreement without official status:

[I] used to have them 3, 4 nights a week and then... it was decided, with DCP pushing it, and [mother's] verbal consent
- that the children would... live with us permanently. Now, it didn't matter how many times I asked DCP for something formal, like "could we have a piece of paper ..." nothing was forthcoming... I need[ed] to be able to access services for the children, ... The children needed occupational therapy, and they needed ... surgery, .... and then I also got child adolescent mental health involved, ... because there was... quite sexualised behaviour - Still no formal paperwork from DCP. (grandparent, interview 22)

Many authors reiterate that families feel unheard in interactions with child protection workers, and recommend that workers seek to understand how families experience the power differences, especially Aboriginal families (Buckley, 2017; Dumbrill, 2010; Herring et al., 2013).

\section{Fighting the system}

In extending the themes here, participants, in various ways, described their engagement with the child protection system in highly conflictual terms, likening it to a "battle" and a "fight" to protect children. For example, this grandparent identified the combative nature of child protection interactions and suggested alternative ways of working:

... [w] lork with the family not against them, ... it is a battle between the family and the child protection authorities, and it shouldn't be. (grandparent, interview 1)

Similarly, this parent used terms such as "adversarial", "battle" and "war" to explain the unhelpful interactions she and her mother experienced with child protection workers in trying to keep connected to the children:

They should have used both parent and grandparent to maintain family connectedness ... that's one of the things that they didn't do- either sub-consciously or deliberately. I tend to think the latter, deliberate, you know, I mean after all ... it's an adversarial situation, you go 
to court, you battle, and that's one of the troubles with child protection it is adversarial not friendly, not helpful to the parent, not helpful to the child, ... like a little war in a room ...they were very unpleasant, one of the first meetings my mother did come along, but she couldn't handle it after that ... the air was so charged and it was really nasty (parent, interview 5)

In another example, after listening to the stories being shared by focus group attendees, this grandmother offered advice from her own extensive lived experiences. She stressed the need to stridently lobby services in order to stay connected to grandchildren:

Write a letter to them...To DCP and say, "Look, this is what's happened." Write a letter to the Family and Children's Court. Go in there and say, "Look, I've got no contact with my grandson, I really want to see him,". As a grandparent you've got a right to see your grandchildren, ... I know this because we've been through it - all my family ... I say "Go ... fight for your babies." (grandparent, focus group 2)

\section{New frameworks or "business as usual"}

Some study participants, including child protection workers and parents, identified that although new policies and frameworks upheld more family-inclusive child protection practice, the implementation of these frameworks was less evident. For example, this parent identified that she had not experienced genuine engagement, inclusion, or clear expectations regarding maintained contact for parents and grandparents:

I really think they should honestly sit down and maybe talk to the grandparents, you know ... and do the family interview .... I don't see why they didn't do that with my mother... I think that should be done in every single case where it is appropriate to do so. And then, you know, ... do a proper family meeting where everyone is included, not excluding, ... have everyone there at the case plan meetings so that it is very clear what Child Safety's expectations are ... and what they want us to do as parents, as grandparents - to ... maintain the contact that we are currently having with them. (parent, interview 12)

The worker below identified the need for more specific legislated or policy-directed involvement of grandparents, and a meaningful commitment, rather than a tokenistic approach to finding kin who could become long-term carers, particularly for Aboriginal children:

I'd like to see something legislated around the Department ... to involve grandparents, like I think ... so quickly ... we move on families and we keep their placement in foster care and they stay there. We don't explore family. We don't explore kin. We're legislated that we have to for Indigenous and Torres Strait Islander families, we don't, it's tokenistic. Just a phone call or an email to a cultural agency [that is] also overworked and underfunded ...-it's tokenistic. (workers, interview 27)

Similarly, another worker identified a lack of implemented policy and practice changes:

I mean Child Safety have now got a new practice framework and they have had lots of training, ... the upper echelons seem to be quite well-informed and committed to the new model, but down on the grassroots, the ground level, ... a lot of times, it's business as usual. (worker, focus group 5)

The above findings reflect assertions made by Smith et al. (2017), and Humphreys et al. (2011, p. 166) in reference to the difficulties of effecting change in frontline child protection services after new policy directives. 


\section{Discussion}

The primary aim of the study reported here was to document the perceptions, narratives and recommendations of participants regarding optimising grandparentgrandchild connections after child protection concerns. Overall, the findings identify that grandparents in this study struggled against the power of child protection departments and workers in seeking to care for and/or protect their grandchildren. Grandparents felt excluded from decision-making about children's placements and contact arrangements, and many participants argued that prescribed practice in partnership with families, and support for them to participate, was not evident.

While recognising the power imbalance between families and authorities in child protection intervention is not new, narratives from participants in this recent study affirm literature that has proliferated across time that families' lived experiences are of feeling fearful, intimidated and disrespected in engagements with child protection workers and systems (Ainsworth \& Berger, 2014; Buckley, 2017; Lonne et al., 2016). While grandparents were keen to remain deeply involved in the lives of their grandchildren, their interactions with child protection workers left them feeling they were in a battle to stay connected. Overall, grandparents in this study did not feel they were involved in family-inclusive processes in the best interests of their grandchildren. The findings align with those of Dumbrill (2010) who argued that workers' inability to manage power differences between themselves and families creates barriers to what might be achieved.

As noted earlier, Herring et al. (2013) and others argue there has been a consistent failure of systems to address discrepancies between Aboriginal and non-Aboriginal Australians' life trajectories and outcomes (SNAICC, 2017, 2018). Key limitations highlighted included the lack of accounting for poverty, trauma and ongoing racism, workers' lack of skills and cultural competencies, and the lack of an inclusive, partnership approach to prevention, protection, placement and ongoing contact (Herring et al., 2013; Child Protection Peak, 2017; SNAICC, 2017, 2018). Literature confirms that family and culture are strong protective factors for Aboriginal families against the intergenerational trauma triggered by the Stolen Generation - from which few families escaped (Lohoar et al., 2014; SNAICC, 2017). Yet surprisingly, findings from this study suggest that evidence of intergenerational trauma, after generations of child removals, can lead to the exclusion of grandparents as carers - rather than the disruption of intergenerational trauma by placing children with safe family members (".. in my experience a lot of the times family and grandparents would be excluded from taking care of children um, because of intergenerational issues"). Such decision-making could explain, in part, the AIHW (2018, p. 48) report that only $68 \%$ of Aboriginal and Torres Strait Islander children in care were placed in accordance with the Child Placement Principle in 2016/2017. Equally, SNAICC (2018, p. 5) argued that community members with knowledge and authority to determine the most appropriate placements are not being consulted. As argued by Kickett-Tucker and Hansen (2017), damage may linger for Aboriginal families because of past forced separations, yet workers may overlook that Aboriginal families possess many strengths and remain influenced by cultural family values and responsibilities.

Herring et al. (2013) recommended processes for achieving change at personal, practice, and organisational levels. These included agencies taking responsibility for workers being trained in Aboriginal history and trauma legacies, and workers doing their own background research to become culturally informed about the local community in which they are working. They recommended that workers recognise and take a stance against racism, reach out into the community through cultural brokers, and spend 
time with community members to build relationships and trust for the best long-term interests of children. These findings support assertions by Herring et al. (2013) that the need for culturally informed, anti-racist child protection practice cannot be overstated.

These findings also support notions that "family-minded", family-inclusive and culturally inclusive policies have not necessarily been translated into changed practice (Morris et al., 2017, p. 58; Smith et al., 2017). The findings contribute to available literature identifying that willing extended families may not be included as partners in decision-making after the involvement of child protection services, whether grandchildren are (or are not) subsequently placed in grandparents' care. In particular, the findings highlight the significant role grandparents seek to play in being a protective factor for grandchildren, and the degree to which they feel unheard. The findings support recommendations by Smith et al. (2017, p. 973) for increased facilitation of workers' critical reflection, to help "destabilise dominant practice orthodoxies and cultures" and effect true cultural change in frontline child protection services.

After identifying children at risk, participants in this study perceived that child protection workers continued to intervene in ways that hampered families' abilities to contribute to decision-making to protect children. Grandparents, and specifically grandmothers, wanted to be listened to, so workers could better understand the unique and complex kin, culture and community contexts in which they are intervening. Participants in this study believed that informed workers who are family-minded, family-inclusive and culturally informed, and who included grandparents in decision-making about the protection of their grandchildren, will help alter the current trajectory of their grandchildren's lives.

\section{Limitations}

The limitations of this study include that, given the focus was on optimising grandparents' ongoing connections with grandchildren after child safety concerns, grandparents who were satisfied with the level of ongoing connections would not have come forward to participate in the study. It is acknowledged that the findings presented here cannot be interpreted as reflecting the everyday relationships between grandparents and child protection workers beyond the sample although findings represent participants' voices across several Australian states.

\section{Conclusion}

The primary aim of the study reported here was to explore and identify ways to optimise connections between grandparents and grandchildren after child safety concerns. What seems evident is that grandparents in this study wanted to be valued by practitioners as partners in safeguarding their grandchildren, yet they often felt caught in a powerful, unsupportive, adversarial system. Recommended here is workers' increased critical awareness of the lived realities for many families, including the impact of the power imbalance between families and child protection workers. Further recommended is increased facilitation by workers of grandparents' ongoing involvement in the lives of their grandchildren, and the genuine implementation of family-inclusive, culturally informed decision-making in child protection practice for the long-term best interests of children.

\section{Acknowledgements}

The authors gratefully acknowledge the willing time investment of all participants and partner organisations. We thank Bindal Elder, Mrs Dorothy Savage, for her guidance.

\footnotetext{
References

Ainsworth, F., \& Berger, J. (2014). Family inclusive child protection practice: The history of the family inclusion network and beyond. Children Australia, 39(2), 60-64. doi:10.1017/cha.2014.1

Alfandari, R. (2017). Partnerships with parents in child protection: A systems approach to evaluate reformative
} 
developments in Israel. British Journal of Social Work, 47(4), 1061-1077. doi.org/10.1093/bjsw/bcw101

Australian Institute of Health and Welfare. (2017). Child protection Australia 2015-16. Retrieved from https://www.aihw.gov.au/reports/child-protection/childprotection-australia-2015-16/contents/table-of-contents

Australian Institute of Health and Welfare. (2018). Child protection Australia 2016-17. Child Welfare Series No. 68. Retrieved from https://www.aihw.gov.au/ getmedia/66c7c364-592a-458c-9ab0-f90022e25368/ aihw-cws-63.pdf.aspx?inline=true

Backhouse, J., \& Graham, A. (2012). Grandparents raising grandchildren: Negotiating the complexities of roleidentity conflict. Child and Family Social Work, 17(3), 306-315. doi/abs/10.1111/j.1365-2206.2011.00781.x

Beddoe, L. \& Cree, V. (2017). The risk paradigm and the media in child protection. In M. Connolly (Ed.), Beyond the risk paradigm in child protection (pp. 15-28). London, UK: Palgrave.

Buckley, H. (2017). Service users as receivers of riskdominated practice. In M. Connolly (Ed.), Beyond the risk paradigm in child protection (pp. 77-90). London, UK: Palgrave.

Carmody, T. (2013). Taking responsibility: A roadmap for Queensland child protection. Queensland Child Protection Commission of Inquiry. Retrieved from https://www.cabinet.qld.gov.au/documents/2013/dec/ response\%20cpcoi/Attachments/report\%202.pdf

Child Protection Peak. (2017). Position statement for Aboriginal kinship care. Queensland Aboriginal and Torres Strait Islander Child Protection Peak Ltd.

Child Protection Systems Royal Commission. (2016). The life they deserve: Child protection systems Royal Commission Report. Retrieved from www.agd.sa.gov.au/ child-protection-systems-royal-commission

Council of Australian Governments (COAG). (2014). Protecting children is everyone's business: National framework for protecting Australia's children 2009-2020. Annual Report 2012-13. Canberra, ACT: Author.

Cox, C. (2014). Personal and community empowerment for grandparent caregivers. Journal of Family Social Work, 17(2), 162-174. doi/abs/10.1080/10522158.2014.880824

Creswell, J. (2014). Research design: Qualitative, quantitative, and mixed methods. Thousand Oaks, CA: Sage.

Department of Prime Minister and Cabinet. (2017). Closing the gap: Prime Minister's report 2017. Canberra, ACT: Author.

Drew, L., \& Silverstein, M. (2007). Grandparents' psychological wellbeing after loss of contact with their grandchildren. Journal of Family Psychology, 21(3), 372-379. doi.org/10.1037/0893-3200.21.3.372

Dumbrill, G. (2010). Power and child protection. The need for a child welfare users' union or association. Australian Social Work, 63(2), 194-206. doi.org/10.1080/03124071003717655

Farmer, E. (2009). What factors relate to good placement in kinship care? British Journal of Social Work, 4O(2), 426-444. doi:10.1093/bjsw/bcp007

Funston, L., Herring, S., \& ACMAG. (2016). When will the Stolen Generation end? A qualitative, critical exploration of contemporary "child protection" practices in Aboriginal and Torres Strait Islander communities. Sex Abuse in Australia and New Zealand, 7(1), 51-58.
Gair, S. (2017). Missing grandchildren: Grandparents' lost contact and implications for social work. Australian Social Work, 70(3), 263-275.

Gair, S., Zuchowski, I., Munns, L., Thorpe, R., \& Henderson, D. (2018). Grandparents matter: Optimising grandparents' involvement after child safety concerns. Child and Family Social Work. Retrieved from https://onlinelibrary.wiley. com/doi/full/10.1111/cfs.12464

Herring , S., Spangaro, J., Lauw, M., \& McNamara, L. (2013). The intersection of trauma, racism, and cultural competence in effective work with Aboriginal people: Waiting for trust. Australian Social Work, 66(1), 104-117. doi/abs/10.1080/0312407X.2012.697566

Human Rights and Equal Opportunity Commission (HREOC). (1997). Bringing them home. Report of the national inquiry into the separation of Aboriginal and Torres Strait Islander children from their families. Sydney, NSW: HREOC.

Humphreys, C., Thiara, R., \& Skamballis, A. (2011). Readiness to change: Mother-child relationship and domestic violence intervention. British Journal of Social Work, 41(1), 166-184. doi:10.1093/bjsw/bcq046

Hunt, J. (2018). Grandparents as substitute parents in the UK. Contemporary Social Science, 13(2), 175-186. doi/abs/10.1080/21582041.2017.1417629

Irizarry, C., Miller, K., \& Bowden, M. (2016). Kinship care: Child safety or easy option? Staff and carers' perspectives. Journal of Family Social Work, 19(3), 199-219. doi/full/10.1080/10522158.2016.1187699?src=recsys

Ivec, M., Braithwaite, V., \& Harris, N. (2012). "Resetting the relationship" in Indigenous child protection: Public hope and private reality. Law \& Policy, 34(1), 80-103. doi/abs/10.1111/j.1467-9930.2011.00354.x

Keddell, E. (2017). Interpreting children's best interests: Needs, attachment and decision-making. Journal of Social Work, 17(3), 324-342. doi/abs/10.1177/1468017316644694

Kickett-Tucker, C., \& Hansen, J. (2017). Ngalang Moort: Family as the building block of community development. In C. Kickett-Tucker, D. Bessarab, J. Coffin, \& M. Wright (Eds.), Mia Mia Aboriginal community development (pp. 199-216). Cambridge, UK: Cambridge University Press.

Liamputtong, P. (2009). Qualitative research methods (3rd ed.). Melbourne, VIC: Oxford University Press.

Lohoar, S., Butera, N., \& Kennedy, E. (2014). Strengths of Australian Aboriginal cultural practices in family life and child rearing. Child Family Community Australia, Paper No. 25. Information Exchange. Retrieved from https://aifs.gov.au/ cfca/sites/default/files/publication-documents/cfca25.pdf

Long, M., \& Sephton, R. (2011). Rethinking the best interests of the child: Voices from Aboriginal child and family welfare practitioners. Australian Social Work, 64(1), 96-112. doi.org/10.1080/0312407X.2010.53554

Lonne, B., Harries, M., Featherstone, B., \& Gray, M. (2016). Working ethically in child protection. Abingdon, UK: Routledge.

Milosevic, A., Thorpe, R., \& Miles, D. (2009). For good or ill, this is my family! What counts for quality in the role for statutory relative foster carers? [Unpublished conference paper (ACCFPP Quality Counts)]. Brisbane, QLD.

Morris, K., White, S., Doherty, P., \& Warwick, L. (2017). Out of time: Theorising family in social work practice. Child and Family Social Work, 22(S3), 51-60. doi:10.1111/cfs.12257 
Morris, K., \& Burford, G. (2017). Engaging families and managing risk in practice. In M. Connolly (Ed.), Beyond the risk paradigm in child protection (pp. 91-108). London, UK: Palgrave.

Parton, N. (2017). Concerns about risk as a major driver of professional practice. In M. Connolly (Ed.), Beyond the risk paradigm in child protection (pp. 3-14). London, UK: Palgrave.

Qu, L., Lahausse, J., \& Carson, R. (2018). Working together to care for kids. A survey of foster and relative/kinship carers (Research Report). Melbourne, VIC: Australian Institute of Family Studies.

Ramsden, K. (2013). Children's perspectives on their own wellbeing: "I don't think they can hear us." Developing Practice, 36(Spring), 18-30.

Raissian, K., \& Bullinger, L. R. (2017). Money matters: Does the minimum wage affect child maltreatment rates? Child and Youth Services Review, 72, 60-70.

Rigby, E., Gair, S., \& Thorpe, R. (2016). Surviving intervention: Grandparents' struggle to maintain contact with grandchildren. Children Australia, 41(2) 98-105.

Secretariat of National Aboriginal and Islander Child Care Inc (SNAICC). (2010). Working and walking together. Melbourne, VIC: Author.

Secretariat of National Aboriginal and Islander Child Care (SNAICC). (2017) The family matters report. Melbourne, VIC: Author.

Secretariat of National Aboriginal and Islander Child Care (SNAICC). (2018). The family matters report 2018. Melbourne, VIC: Author.

Smith, M., Cree, V., MacRae, R., Sharp, D., Wallace, E., \& O' Halloran, S. (2017). Social suffering: Changing organisational culture in children and families social work through critical reflection groups - Insights from Bourdieu. British Journal of Social Work, 47(4), 973-988. doi.org/10.1093/bjsw/bcw087

Tarrant, A., Featherstone, B., O'Dell, L., \& Fraser, C. (2017). "You try to keep a brave face but inside you are in bits": Grandparent experiences of engaging with professionals in Children's Services. Qualitative Social Work, 16(3), 351-366. doi/abs/10.1177/1473325015615397

Thoburn, J., Lewis, A., \& Shemmings, D. (1995). Paternalism or partnership? Family involvement in the child protection process. London, UK: HMSO.

Thomson, G., Cameron, R., \& Fuller-Thomson, E. (2013). Walking the red road. The role of First Nation grandparents in promoting cultural wellbeing. International Journal of Aging and Human Development, 76(1), 55-78. doi.org/10.2190/AG.76.1.c

Winokur, M., Holtan, A., \& Batchelder, K. E. (2014). Kinship care for the safety, permanency, and well-being of children removed from the home for maltreatment: A systematic review. Campbell Collaboration, 1. doi:10.1002/14651858.CD006546.pub3

Zuchowski, I., Gair, S., Henderson, D., \& Thorpe, R. (2018). Convenient yet neglected: The role of grandparent kinship carers. British Journal of Social Work. https://doi.org/10.1093/bjsw/bcy085 